\title{
Exposure to chronic mild stress prevents kappa opioid-mediated reinstatement of cocaine and nicotine place preference
}

\author{
Ream Al-Hasani ${ }^{1,2}$, Jordan G. McCall ${ }^{1,3}$ and Michael R. Bruchas ${ }^{1,2,3,4 *}$ \\ ' Basic Research Division, Department of Anesthesiology, Washington University School of Medicine, St. Louis, MO, USA \\ ${ }^{2}$ Department of Anatomy and Neurobiology, Washington University School of Medicine, St. Louis, MO, USA \\ ${ }^{3}$ Division of Biological and Biomedical Sciences, Washington University School of Medicine, St. Louis, MO, USA \\ ${ }^{4}$ Washington University Pain Center, Washington University School of Medicine, St. Louis, MO, USA
}

\section{Edited by:}

Thibault Renoir, Florey Institute of Neuroscience and Mental Health, Australia

\section{Reviewed by:}

Mariela Fernanda Perez, Universidad Nacional de Cordoba, Argentina Lynn G. Kirby, Temple University School of Medicine, USA

\section{${ }^{*}$ Correspondence:}

Michael R. Bruchas, Basic Research Division, Department of

Anesthesiology and Department of Anatomy and Neurobiology, Washington University School of Medicine, 660 South Euclid Avenue, Box 8054, St. Louis, MO 63110, USA e-mail: bruchasm@wustl.edu
Stress increases the risk of drug abuse, causes relapse to drug seeking, and potentiates the rewarding properties of both nicotine and cocaine. Understanding the mechanisms by which stress regulates the rewarding properties of drugs of abuse provides valuable insight into potential treatments for drug abuse. Prior reports have demonstrated that stress causes dynorphin release, activating kappa opioid receptors (KOR) in monoamine circuits resulting in both potentiation and reinstatement of cocaine and nicotine conditioned place preference. Here we report that kappa opioid-dependent reinstatement of cocaine and nicotine place preference is reduced when the mice are exposed to a randomized chronic mild stress (CMS) regime prior to training in a conditioned place preference-reinstatement paradigm. The CMS schedule involves seven different stressors (removal of nesting for $24 \mathrm{~h}, 5 \mathrm{~min}$ forced swim stress at $15^{\circ} \mathrm{C}, 8 \mathrm{~h}$ food and water deprivation, damp bedding overnight, white noise, cage tilt, and disrupted home cage lighting) rotated over a 3-week period. This response is KOR-selective, as CMS does not protect against cocaine or nicotine drug-primed reinstatement. This protection from reinstatement is also observed following sub-chronic social defeat stress, where each mouse is placed in an aggressor mouse home cage for a period of 20 min over 5 days. In contrast, a single acute stressor resulted in a potentiation of KOR-induced reinstatement, as previously reported. Prior studies have shown that stress alters sensitivity to opioids and prior stress can influence the pharmacodynamics of the opioid receptor system. Together, these findings suggest that exposure to different forms of stress may cause a dysregulation of kappa opioid circuitry and that changes resulting from mild stress can have protective and adaptive effects against drug relapse.

Keywords: kappa opioid receptor, cocaine, nicotine, stress, conditioned place preference

\section{INTRODUCTION}

It is well-established that stress increases the risk of drug abuse, relapse to drug seeking, and potentiates the rewarding properties of cocaine (Covington and Miczek, 2001; McLaughlin et al., 2003; Redila and Chavkin, 2008; Bruchas et al., 2010). Previous studies have implicated a critical role for dynorphin/kappa opioid systems in the mediation of stress-induced behaviors including reinstatement of drug seeking in both place preference and self-administration animal models. Studies have shown that stressinduced reinstatement to alcohol, cocaine, and nicotine seeking is absent in kappa opioid receptor (KOR) $\mathrm{KO}$ and dynorphin $\mathrm{KO}$ mice as well as following pretreatment with KOR antagonists (Beardsley et al., 2005; Redila and Chavkin, 2008; Walker and Koob, 2008; Walker et al., 2011; Jackson et al., 2013). However, while numerous models of acute stress reinstate drug seeking through dynorphin/KOR activation, the effects of prior repeated stress exposure, and various magnitudes of stress exposure on KOR-mediated reinstatement has not been examined.
The dynorphin/KOR system is composed of prodynorphin peptides and KOR, a seven-transmembrane spanning $\mathrm{G}_{\mathrm{i} / \mathrm{o}}$ protein-coupled receptor (GPCR). In addition to the classical inhibitor effects on adenylate cyclase activity, KOR also couples to mitogen-activated protein kinase pathways (Bruchas et al., 2010; Al-Hasani and Bruchas, 2011) to mediate various behavioral effects (Bruchas et al., 2011; Potter et al., 2011). It is thought that stress causes dynorphin release activating KOR within monoamine nuclei (ventral tegmental area, dorsal raphe, locus coeruleus) and their projection targets (extended amygdala, nucleus accumbens, etc.; Wise, 2004; Zhang et al., 2005; Carlezon et al., 2006; Gehrke et al., 2008; Land et al., 2008, 2009; Ebner et al., 2010; Bruchas et al., 2011; Al-Hasani et al., 2013; Graziane et al., 2013). The KORmediated reduction in dopamine and serotonin activity results in dysphoria-like behavior that drives reinstatement of drug seeking to relieve this negative affective state. KORs are highly regulated via G-protein-coupled receptor kinase (GRK) phosphorylation and desensitization mechanisms. In opioid receptors this cellular 
regulatory system acts to remove receptor-G-protein activation, and promotes tolerance, arrestin signaling and/or receptor recycling (McLaughlin etal., 2004; Al-Hasani and Bruchas, 2011; Williams et al., 2013).

Chronic mild stress (CMS) is a widely adopted animal model for inducing depression- and anxiety-like behaviors because it mimics the unpredictable intermittent stress exposure that humans experience, for complete review see Hill et al. (2012). The model utilizes repeated, randomized stress events, over the course of several weeks to mimic the unpredictable nature of mild stress experience (Elizalde et al., 2008; Peng et al., 2012; Tye et al., 2013). Numerous studies have demonstrated that various types of CMS models act to alter neurotransmitter systems including monoamine (dopamine, serotonin, and norepinephrine), gamma-aminobutyric acid (GABA), and glutamatergic transmission (Rasheed et al., 2008; Vancassel et al., 2008; Tye et al., 2013). However, the role of CMS on opioid system regulation is not as well-known, with only a few reports showing that dynorphin and enkephalin opioid neuropeptide mRNA remain relatively unchanged in CMS models in various brain regions (Bertrand et al., 1997; Bergström etal., 2008). More recent reports have shown that repeated stress can dysregulate the effects of KOR signaling within dorsal raphe serotonergic circuits (Lemos et al., 2012a) but the functional consequences of repeated stress exposure or CMS compared to acute and sub-chronic stressors on kappa opioid-dependent behaviors has not been investigated.

Here we determined how different types of exposure to stress (acute, sub-chronic, and chronic) impact subsequent kappa opioid-mediated reinstatement of cocaine and nicotine place preference. We determined how different forms of stress, including a 3-week CMS, sub-chronic social defeat stress (SDS), and acute forced swim stress (FSS), impact kappa opioid-induced reinstatement. We found that the initial cocaine and nicotine conditioned place preference were unchanged in sub-chronic stress and CMS exposure, however, KOR-induced cocaine and nicotine reinstatement was absent in mice that were pre-exposed to CMS, in contrast to acute stress, which caused potentiated KOR-reinstatement. In addition, we found that cocaine and nicotine drug-primed reinstatement is not affected by pre-exposure to stress, suggesting that this protective ablation of KOR-induced reinstatement by CMS, selectively affects KOR-mediated behavioral responses.

\section{MATERIALS AND METHODS ANIMAL SUBJECTS}

Male C57BL/6 wild-type mice, bred locally and maintained in Washington University mouse facility (20-30 g) were used for all experiments. All mice were group-housed within the Animal Core Facility at Washington University in St. Louis, given access to food pellets and water ad libitum, and maintained in specific pathogenfree housing. Mice were transferred at least 1 week before testing into a colony room adjacent to the behavioral testing room to acclimatize to the study environment and prevent stress during conditioning phases. Housing rooms were illuminated on a $12-\mathrm{h}$ light/dark cycle with lights on at $7 \mathrm{AM}$. All animal procedures were approved by the Animal Care and Use Committee of Washington University in St. Louis, in accordance with the National Institutes of Health Guide for the Care and Use of Laboratory Animals.

\section{DRUGS}

Cocaine $\mathrm{HCl}$ and racemic U50,488 methanesulfonate were provided by the National Institute on Drug Abuse and Drug Supply Program and in some instances Sigma Aldrich (St. Louis, MO, USA). Nicotine hydrogen tartrate salt was purchased from Sigma Aldrich (St. Louis, MO, USA), dissolved in phosphate buffered solution. The free base form of nicotine was used for calculating all injection doses. All drugs were dissolved in saline unless otherwise indicated.

\section{CONDITIONED PLACE PREFERENCE AND REINSTATEMENT PARADIGM}

Mice were trained in an unbiased, balanced three-compartment conditioning apparatus and the reinstatement of cocaine place preference (CPP) paradigm was conducted as previously described (Land et al., 2009; Bruchas et al., 2011; Al-Hasani et al., 2013). On pre-conditioning day mice were allowed free access to all three chambers for $30 \mathrm{~min}$ (cocaine CPP) and $20 \mathrm{~min}$ (nicotine CPP). Time spent in each compartment was recorded with a video camera (ZR90; Canon) and analyzed using Ethovision 8.5 (Noldus). Mice were randomly assigned to saline and drug compartments and received a saline injection in the morning $(10 \mathrm{ml} / \mathrm{kg}$, s.c.) and cocaine $(15 \mathrm{mg} / \mathrm{kg}$, s.c.) or nicotine $(0.5 \mathrm{mg} / \mathrm{kg}$, s.c.; Jackson et al., 2013) injection in the afternoon, at least $4 \mathrm{~h}$ after the morning training on two consecutive days for nicotine conditioning and three consecutive days for cocaine conditioning. To test for cocaine place preference the mice were allowed free access to the three compartments. Scores were calculated by subtracting the time spent in the drug-paired compartment, post-test minus the pre-test. Mice were considered to have conditioned if the conditioning score was within $15-85 \%$ of total conditioning time, approximately 50 and $80 \%$ of mice reached this criteria for nicotine and cocaine conditioning, respectively. This was followed by 2 days (nicotine) or 3 days (cocaine) of extinction training during which saline $(10 \mathrm{ml} / \mathrm{kg}$, s.c. $)$ was injected in both the morning and afternoon prior to placement into isolated conditioning compartments. Mice were then tested for extinction of place preference with free access to all three chambers. Mice were considered to have extinguished cocaine and nicotine preference if scores fell within $15 \%$ of their initial preference scores, approximately $98 \%$ of mice met this criteria. Mice that did not meet these criteria were excluded from the study and mice that met these criteria and extinguished continued on to the reinstatement phase.

On reinstatement test day mice were injected with KOR agonist, U50,488 (5 mg/kg, i.p.), placed in their home cage for $30 \mathrm{~min}$ (cocaine $\mathrm{CPP}$ ) or $20 \mathrm{~min}$ (nicotine $\mathrm{CPP}$ ) as previously described (Redila and Chavkin, 2008; Land et al., 2009; Al-Hasani et al., 2013), after which they were placed in the CPP apparatus and allowed free access to all three compartments for reinstatement expression. Reinstatement was measured as time (s) in drugpaired chamber on reinstatement test day minus time spent in drug-paired chamber following extinction training. On the following day, all mice were exposed to a priming injection of cocaine $(15 \mathrm{mg} / \mathrm{kg}$, s.c. $)$ or nicotine $(0.5 \mathrm{mg} / \mathrm{kg}$, s.c. $)$ to test for drug-primed reinstatement and placed in the apparatus with free access to all compartments. Reinstatement scores were calculated by subtracting the time spent in the cocaine or nicotine 
side post-reinstatement minus the extinction test as previously described (Land et al., 2009; Bruchas et al., 2011).

\section{ACUTE STRESS}

During reinstatement (day 10) mice were subjected to FSS in which they were placed in an $18 \mathrm{~cm}$ deep bucket of water at $30^{\circ} \mathrm{C}$ and allowed to swim for upto $6 \mathrm{~min}$. Mice were removed immediately if they appeared to be at risk of drowning. After a 5 min dry off and recovery period mice were injected with U50, 488 (5 mg/kg, i.p.) in the home cage for $30 \mathrm{~min}$ and then placed in the CPP chambers, with access to all three compartments to access reinstatement to cocaine place preference.

\section{SUB-CHRONIC SOCIAL DEFEAT STRESS}

Social defeat stress was performed as previously described (Bruchas et al., 2011). From the afternoon of the conditioning post-test (day 5) until post-extinction day (day 9) mice were placed in the home cage of an aggressor mouse for a period of $20 \mathrm{~min}$ in the afternoon $2 \mathrm{~h}$ following extinction or post-testing (typically from 4 to $6 \mathrm{PM})$. Mice were monitored carefully for severe injury during SDS and were removed if necessary. No mice met this criterion in this study. In addition, as previously described (Land et al., 2009; Bruchas et al., 2011) all mice are observed and tracked to receive similar bouts of aggression and exhibit characteristic social defeat postures (McLaughlin et al., 2006; Land et al., 2009) to ensure similar stress exposure in each treatment group. On day 10 mice were injected with U50,488 (5 mg/kg, i.p.) in the home cage and then placed in the CPP chambers 30 min later to access reinstatement to cocaine seeking. On day 11 , for drugprimed reinstatement, mice were injected with cocaine $(15 \mathrm{mg} / \mathrm{kg}$, i.p.) and immediately placed in the testing chambers.

\section{CHRONIC MILD STRESS PARADIGM}

In order to model randomized mild stress exposure, we adapted a previously validated CMS paradigm. Stressors were randomly assigned during the 3-week stress period (outlined in Table 1) prior to conditioned place preference/reinstatement procedure. During reinstatement phase the mice were injected with U50,488 $(5 \mathrm{mg} / \mathrm{kg}$, i.p.) in the home cage $(30 \mathrm{~min})$ and then placed in the CPP chambers to assess reinstatement to cocaine place preference. On the following day, mice were injected with cocaine $(15 \mathrm{mg} / \mathrm{kg}$, s.c.) or nicotine $(0.5 \mathrm{mg} / \mathrm{kg}$, s.c.) priming injection and again allowed free access to all three chambers to determine drug primeinduced reinstatement of place preference.

\section{LOCOMOTOR ACTIVITY}

During the 3-day conditioning period and during reinstatement test days, locomotor activity was recorded as distance traveled $(\mathrm{cm})$ throughout the 30 min period using video tracking (Canon) of animal movement and Ethovision 8.5 software analysis (Noldus). During the conditioning period the total distance $(\mathrm{cm})$ on conditioning days are represented. During reinstatement post-test trials distance $(\mathrm{cm})$ is represented as $5 \mathrm{~min}$ bins throughout the $30 \mathrm{~min}$ test period.

\section{DATA ANALYSES AND STATISTICS}

Data were expressed as means \pm SEM. All raw data were calculated via Ethovision video tracking and then place preference or locomotor data were calculated as described. Data were normally distributed, and differences between groups were determined using Student's independent $t$-tests, one-way ANOVA, or two-way ANOVA as appropriate. ANOVA's were followed by post hoc Bonferroni comparisons if the main effect was significant at $p<0.05$. Statistical analyses were conducted using GraphPad Prism 5.0F (GraphPad, San Diego, CA, USA).

\section{RESULTS \\ ACTIVATION OF KAPPA OPIOID RECEPTORS FOLLOWING ACUTE STRESS POTENTIATES REINSTATEMENT OF COCAINE PLACE PREFERENCE}

It has previously been shown that FSS is sufficient to induce reinstatement and potentiation to drug seeking in a KOR-dependent manner (McLaughlin et al., 2003; Schindler et al., 2012; Smith et al., 2012). Furthermore, stress-induced activation of KOR reinstates nicotine, alcohol, and cocaine seeking (Bruchas et al., 2010; Van Bockstaele et al., 2010; Wee and Koob, 2010; Graziane et al., 2013). In this study, we determined whether acute exposure to a single swim stress would prevent or potentiate a subsequent KORmediated reinstatement of CPP. Mice were subjected to cocaine conditioning, extinction, and reinstatement as described. On reinstatement day mice were exposed to swim stress for up to $6 \mathrm{~min}$, were injected with KOR agonist U50,488 (5 mg/kg, i.p) 5 min following recovery, and then placed in the CPP chamber 30 min later (Figure 1A). Mice subjected to FSS prior to KOR activation by U50,488 showed significant and robust potentiation of reinstatement to cocaine seeking when compared to mice that were not subjected to FSS but that were injected with only U50,488 to induce reinstatement (Figure 1B, $n=8-15$ ${ }^{* * *} p<0.001$, no stress and U50 vs. FSS and U50; one-way ANOVA, Bonferroni post hoc test). Locomotor activity during the reinstatement test was measured and the combination of FSS, followed by KOR-induced reinstatement to cocaine seeking showed a reduction in locomotor activity when compared to both the non-stressed group and the FSS alone group (Figure 1C). These data suggest that acute stress exposure induces a potentiation of KOR agonist-induced reinstatement of cocaine place preference.

\section{SUB-CHRONIC STRESS EXPOSURE BLOCKS SUBSEQUENT KOR AGONIST-INDUCED REINSTATEMENT OF COCAINE PLACE PREFERENCE}

To determine the effects of multiple rounds of stress exposure on KOR-induced reinstatement, mice were subjected to $20 \mathrm{~min}$ of SDS at the end of the day during extinction training and prior to the reinstatement phase. On day 10, the reinstatement test day, a single dose of U50,488 (5 mg/kg, i.p.) was administered to induce reinstatement of cocaine place preference (Figure 2A). Prior exposure to sub-chronic SDS resulted in a significant block of U50,488 induced reinstatement of cocaine place preference (Figure 2B: ${ }^{\star} p<0.05$, no stress and U50,488 vs. SDS and U50,488, ${ }^{*} p<0.01$, SDS and U50,488 vs. SDS and cocaine; one-way ANOVA followed by Bonferroni post hoc test, $n=12-16)$. This inhibition of reinstatement was selective for activation of KOR because a priming injection of cocaine $(15 \mathrm{mg} / \mathrm{kg}$, s.c.) still caused significant reinstatement of cocaine CPP following exposure to 


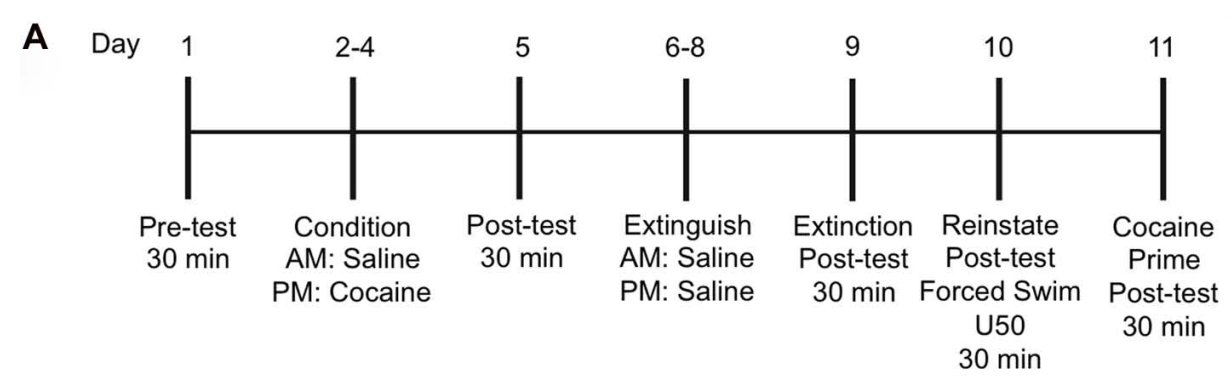

B

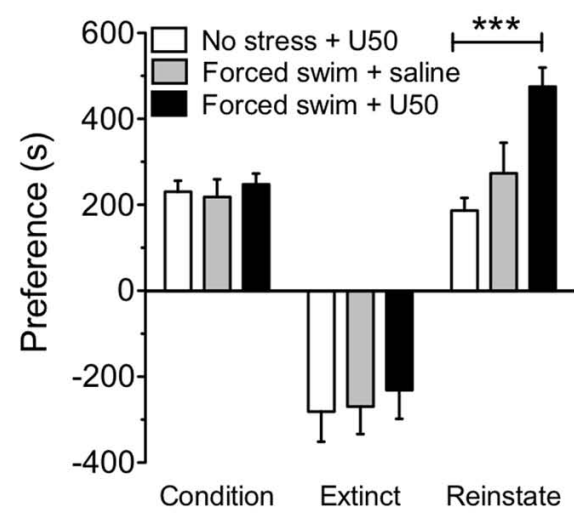

FIGURE 1 | Acute forced swim stress potentiates U50,488-induced reinstatement of cocaine place preference. (A) Timeline of cocaine place preference-reinstatement experimental paradigm. (B) Cocaine preference scores (day 5), calculated as post-test minus pre-test on the cocaine-paired side (condition) and U50,488-induced (5 mg/ $/ \mathrm{kg}$, i.p.) reinstatement scores (day 10) of extinguished place preference (reinstate). Data show a significant potentiation in KOR-reinstatement following forced swim stress and U50,488. the sub-chronic SDS paradigm (Figure $2 \mathbf{B} ;{ }^{* *} p<0.01$, SDS and U50 vs. SDS with cocaine, $n=12-16)$. We also measured locomotor activity during the $30 \mathrm{~min}$ reinstatement phase. Both the non-stress + U50,488 group and the SDS + U50,488 group show a similar KOR-mediated reduction in locomotor over the 30 min period, supporting the notion that prevention of reinstatement by pre-exposure to stress, is not due to additional alterations in mouse locomotor activity (Figure 2C). In contrast, as shown in previous studies (Reith, 1986; Tolliver et al., 1994; Giros et al., 1996; Sora et al., 1998; Zhang et al., 2002) locomotor activity was significantly elevated in mice reinstated with cocaine (\#\# $p<0.01$ and ${ }^{\# \#} p<0.005$, SDS and U50,488 vs. SDS and cocaine at 5 and 10 min time point, respectively; ${ }^{* *} p<0.01$, no stress and U50,488 vs. SDS and U50,488 at 10 min time point; ${ }^{* * *} p<0.005$, SDS and cocaine vs. both no stress and U50 and SDS and U50,488 at $15 \mathrm{~min} ;{ }^{* * *} p<0.001$ SDS and cocaine vs. both no stress and U50 and SDS and U50,488 at 20,25, and 30 min time points; two-way ANOVA followed by Bonferroni post hoc test, $n=12-16)$. Taken together, these data suggest that exposure to a sub-chronic repeated SDS causes a significant prevention of kappa agonist-induced reinstatement of cocaine place preference.
C

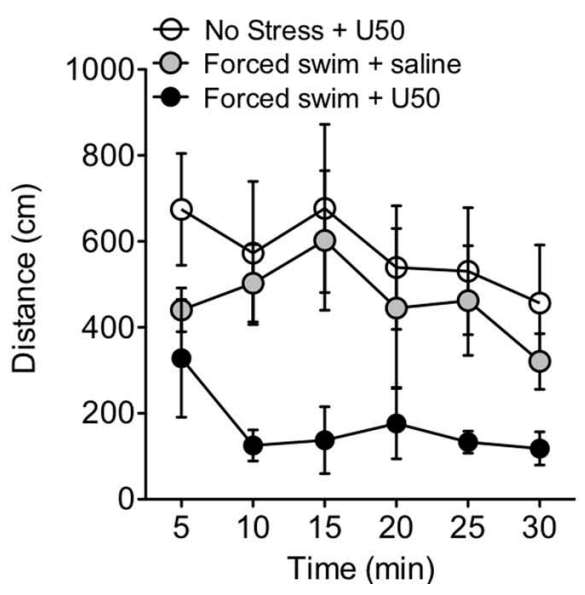

Groups are defined in the figures as their final reinstatement grouping $(\cup 50=\cup 50,488)$. Data represent the mean preference $(s) \pm S E M, n=8-15$ (*** $p<0.001$, no stress and U50 vs. forced swim stress and U50; one-way ANOVA followed by Bonferroni post hoc test). (C) Locomotor activity measured as distance traveled $(\mathrm{cm})$ during the $30 \mathrm{~min}$ reinstatement trial. Data represent the mean preference (s) \pm SEM, $n=8-15$.

\section{CHRONIC MILD STRESS PROTECTS AGAINST U50,488-INDUCED REINSTATEMENT TO COCAINE AND NICOTINE PLACE PREFERENCE}

Kappa opioid receptor agonists and stress have been shown in numerous models to affect the magnitude of cocaine and nicotine place preference as well as cause reinstatement of cocaine and nicotine preference behavior (Redila and Chavkin, 2008; Land et al., 2009; Bruchas et al., 2010; Al-Hasani and Bruchas, 2011; Al-Hasani et al., 2013; Jackson et al., 2013). However, it is not known how repeated CMS ultimately influences cocaine and nicotine preference, or how CMS influences subsequent KOR or drug-primed reinstatement of cocaine or nicotine reinstatement. Therefore, we determined how a CMS paradigm adapted from Elizalde et al. (2008); Peng etal. (2012), and Tye etal. (2013) (Table 1 and Figures $3 \mathrm{~A}$ and $\mathbf{4 A}$ ) influences cocaine and nicotine conditioning, as well as KOR-induced reinstatement of cocaine and nicotine CPP. The CMS paradigm involved a random assignment of seven mild stressors during a 3-week period (see Table 1) prior to the cocaine or nicotine $\mathrm{CPP} /$ reinstatement training protocol.

There was no significant difference between the no stress and CMS-exposed groups in the magnitude of the initial cocaine $(15 \mathrm{mg} / \mathrm{kg}$, s.c. $)$ or nicotine $(0.5 \mathrm{mg} / \mathrm{kg}$, s.c. $)$ conditioned place preference scores. This finding suggests that exposure to CMS does 


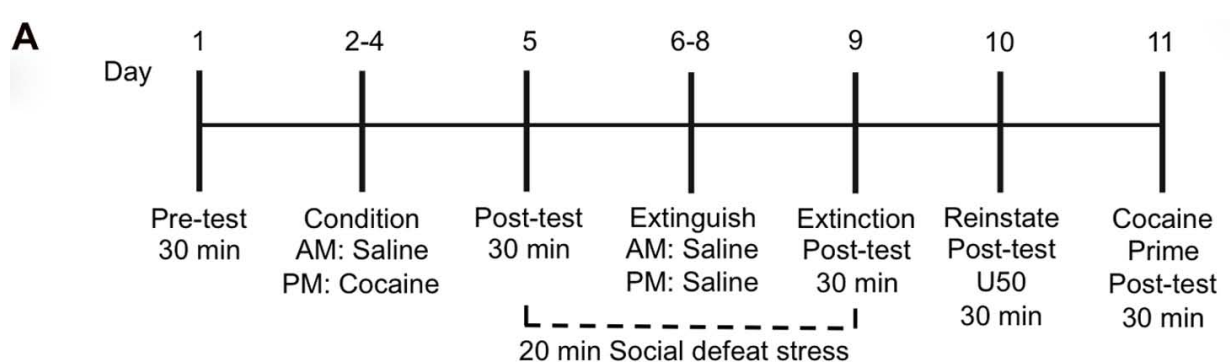

(4-6 PM)

B

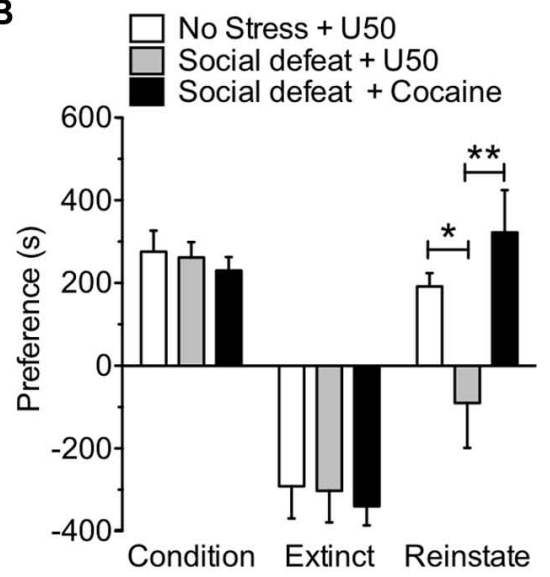

FIGURE 2 | Exposure to sub-chronic social defeat stress prevents U50,488-induced reinstatement of cocaine place preference. (A) Timeline of cocaine place preference-reinstatement experiment. (B) Cocaine preference scores (day 5) calculated as post-test minus pre-test on the cocaine-paired side (condition) and U50,488-induced (5 mg/kg, i.p.) reinstatement scores (day 10) of extinguished place preference (reinstate), calculated as reinstatement test day minus extinction post-test day. Groups are defined in the figures as their final reinstatement grouping $(U 50=U 50,488)$. Data show a significant attenuation in KOR-reinstatement following sub-chronic social defeat stress. Data represent the mean preference (s) \pm SEM, $n=12-16\left({ }^{*} p<0.05\right.$, no stress and U50,488 vs. social defeat stress and $U 50,488,{ }^{* *} p<0.01$, social defeat stress and
C

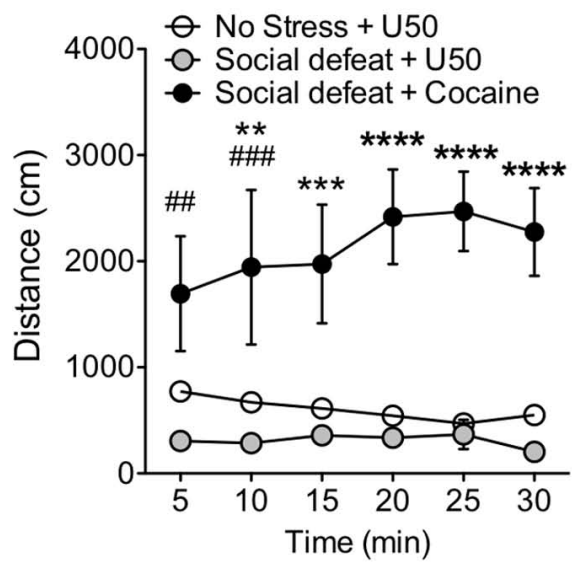

U50,488 vs. social defeat stress and cocaine; one-way ANOVA followed by Bonferroni post hoc test). (C) Locomotor activity measured as distance traveled $(\mathrm{cm})$ during the 30 min reinstatement trial. Data represent the mean

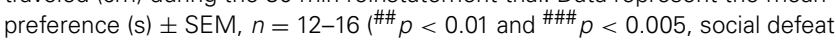
stress and U50,488 vs. social defeat stress and cocaine at 5 and $10 \mathrm{~min}$ time point, respectively; ${ }^{* *} p<0.01$, no stress and $U 50,488 \mathrm{vs}$. social defeat stress and $\cup 50,488$ at 10 min time point; ${ }^{* * *} p<0.005$, social defeat stress and cocaine vs. both no stress and U50 and social defeat stress and U50,488 at $15 \mathrm{~min} ;{ }^{* * * *} p<0.001$ social defeat stress and cocaine vs. both no stress and U50 and social defeat stress and U50,488 at 20, 25, and 30 min time points; two-way ANOVA followed by Bonferroni post hoc test) not effect the subsequent conditioned rewarding effects of cocaine or nicotine (Figures 3B and 4B). Extinction rates of place preference between no stress, SDS-exposed and CMS-exposed groups were not significantly changed. In contrast, following extinction of either cocaine or nicotine place preference in CMS groups, KOR-induced reinstatement of both cocaine and nicotine place preference was significantly reduced (Figure $3 \mathrm{~B}$ : ${ }^{\star} p<0.05$, no stress and U50,488 vs. stress and U50,488; Student's $t$-test, $n=7$;

Table 1 |Three-week chronic mild stress schedule.

\begin{tabular}{|c|c|c|c|c|c|c|c|}
\hline Week & Day 1 & Day 2 & Day 3 & Day 4 & Day 5 & Day 6 & Day 7 \\
\hline 1 & $\begin{array}{l}\text { 17:00 to next day: } \\
\text { damp bedding }\end{array}$ & $4 \mathrm{~h}$ white noise & 8 h cage tilt & $\begin{array}{l}\text { Continuous light } \\
24 \mathrm{~h}\end{array}$ & $\begin{array}{l}\text { Removal of } \\
\text { nesting } 24 \mathrm{~h}\end{array}$ & $\begin{array}{l}\text { Food and water } \\
\text { deprivation } 8 \mathrm{~h}\end{array}$ & $\begin{array}{l}\text { Swimming at } 4^{\circ} \mathrm{C} \\
\text { for } 5 \mathrm{~min}\end{array}$ \\
\hline 2 & $\begin{array}{l}\text { Continuous light } \\
24 \mathrm{~h}\end{array}$ & $\begin{array}{l}\text { 17:00 to next day: } \\
\text { damp bedding }\end{array}$ & $\begin{array}{l}\text { Food and water } \\
\text { deprivation } 8 \mathrm{~h}\end{array}$ & $\begin{array}{l}\text { Swimming at } 4^{\circ} \mathrm{C} \\
\text { for } 5 \mathrm{~min}\end{array}$ & 8 h cage tilt & $4 \mathrm{~h}$ white noise & $\begin{array}{l}\text { Removal of nest- } \\
\text { ing } 24 \mathrm{~h}\end{array}$ \\
\hline 3 & $\begin{array}{l}\text { Swimming at } 4^{\circ} \mathrm{C} \\
\text { for } 5 \mathrm{~min}\end{array}$ & $\begin{array}{l}\text { Continuous light } \\
24 \mathrm{~h}\end{array}$ & 8 h cage tilt & $\begin{array}{l}\text { Removal of } \\
\text { nesting } 24 \mathrm{~h}\end{array}$ & $4 \mathrm{~h}$ white noise & $\begin{array}{l}\text { Food and water } \\
\text { deprivation } 8 \mathrm{~h}\end{array}$ & $\begin{array}{l}\text { 17:00 to next day: } \\
\text { damp bedding }\end{array}$ \\
\hline
\end{tabular}

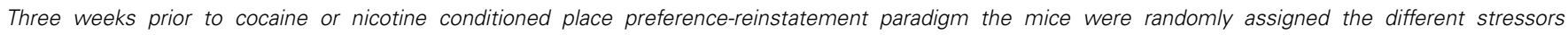
highlighted in the table. Paradigm is modified from Elizalde etal. (2008); Peng etal. (2012), and Tye etal. (2013). 


\section{A}

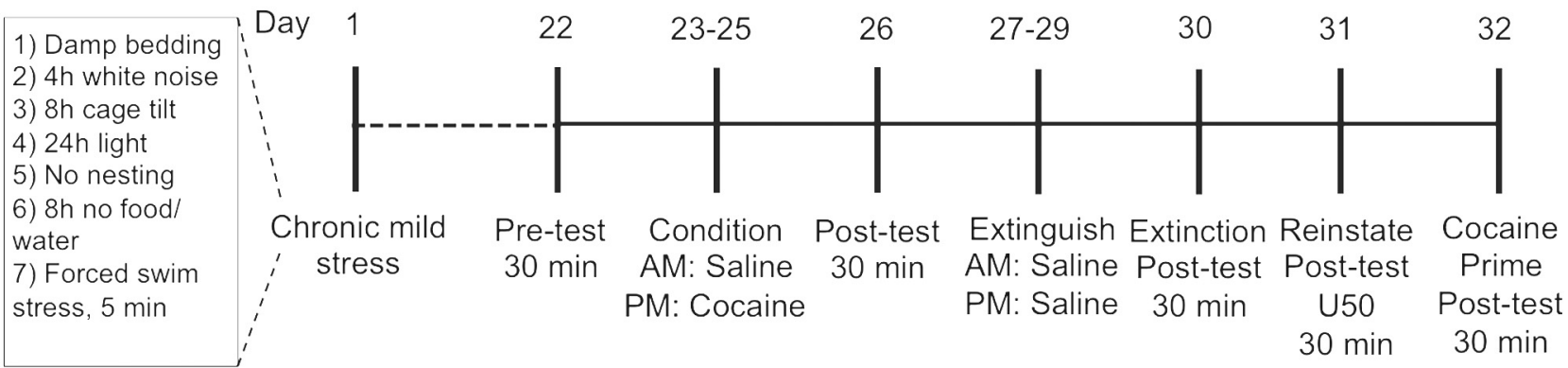

B

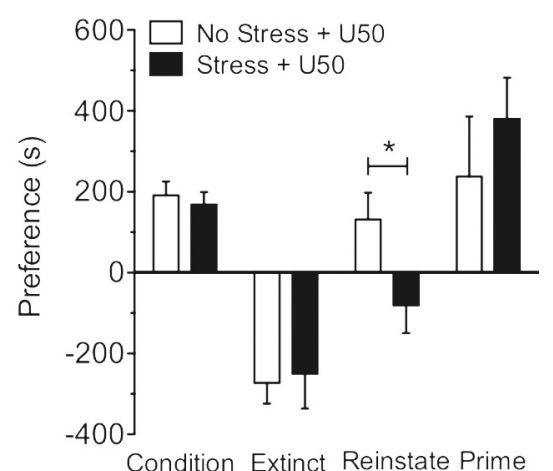

C

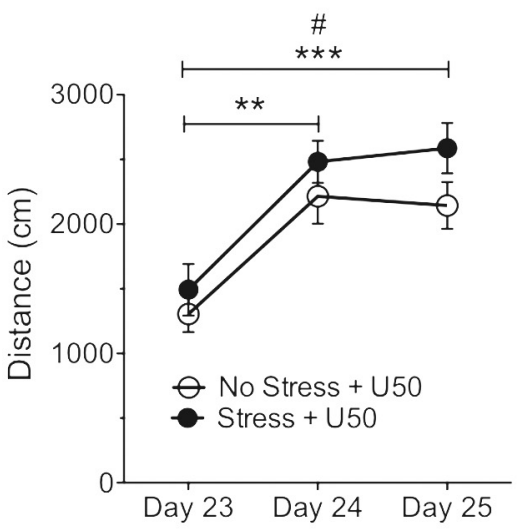

D

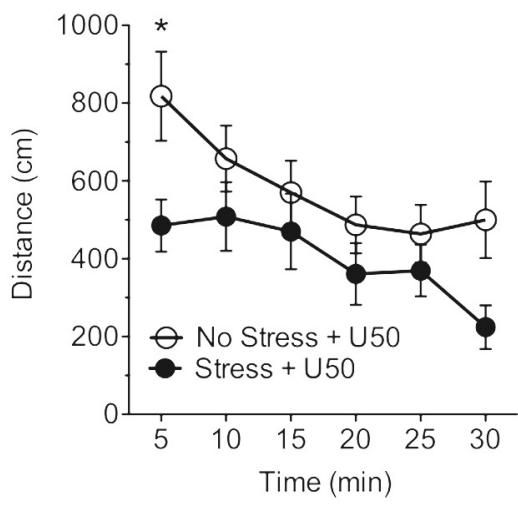

FIGURE 3 | Exposure to chronic mild stress blocks U50,488-induced but not cocaine-primed reinstatement of cocaine place preference. (A) Timeline of cocaine place preference-reinstatement experiment. (B) Cocaine preference scores (day 26), calculated as post-test minus pre-test on the cocaine-paired side (condition), U50,488-induced (5 mg/kg, i.p.) reinstatement scores (reinstate, day 31 ), or cocaine-induced (15 mg/kg, i.p) reinstatement (prime, day 32) of extinguished place preference. Data show a significant attenuation in U50,488-induced but not cocaine-primed reinstatement to cocaine seeking following chronic mild stress. Groups are defined in the figures as their final reinstatement grouping $(U 50=U 50,488)$.Data represent the mean preference (s) \pm SEM, $n=7\left({ }^{*} p<0.05\right.$, no stress and U50,488 vs stress and U50,488; Unpaired Student's $t$-test). (C) Locomotor activity measured as distance traveled $(\mathrm{cm})$ during three cocaine conditioning days. Data represent the mean preference (s) \pm SEM, $n=7$ ( ${ }^{\#} p<0.05$ day 23 vs. day 25 in the no stress group; ${ }^{* *} p<0.01$ day 23 vs. day 24 and ${ }^{* *} p<0.005$ day 23 vs. day 25 between stress group; one-way ANOVA followed by Bonferroni post hoc test). (D) Locomotor activity measured as distance traveled $(\mathrm{cm})$ during reinstatement. Data represent the mean preference (s) \pm SEM, $n=7\left({ }^{*} p<0.05\right.$ at 5 min time point in the no stress group vs. CMS group; two-way ANOVA followed by Bonferroni post hoc test).
Figure 4B: ${ }^{\star} p<0.05$, Student's $t$-test, $n=5-8$. While CMS protected against U50,488-induced reinstatement it had no significant effect on cocaine or nicotine drug-primed reinstatement; indicating that this protective effect of CMS was selective for KOR agonist-induced reinstatement. Locomotor activity was measured during the 3-day conditioning period to determine if exposure to 3 weeks of CMS alters the locomotor response to nicotine $(0.05 \mathrm{mg} / \mathrm{kg}$, s.c.) and cocaine $(15 \mathrm{mg} / \mathrm{kg}$, s.c. $)$. No significant differences in locomotor activity were found between no stress group and the CMS group following cocaine treatment (Figure 3C). As predicted, distance traveled significantly increased over the 3-day cocaine conditioning period, as previously shown (Zhang et al., 2002; Tzschentke, 2007; Figure 3C: ${ }^{\#} p<0.05$ day 23 vs. day 25 in the no stress group; ${ }^{\star *} p<0.01$ day 23 vs. day 24 and ${ }^{\star * *} p<0.005$ day 23 vs. day 25 between stress group; one-way ANOVA followed by Bonferroni post hoc test, $n=7)$. However, nicotine-induced elevations in locomotor activity were significantly reduced following CMS on the second and third day of nicotine conditioning (Figure 4C: ${ }^{\star} p<0.05$, no stress vs. CMS as compared to the no-CMS group; two-way ANOVA followed by Bonferroni post hoc test, $n=5-8$ ). Locomotor activity was also measured during U50induced reinstatement in both the nicotine and cocaine groups. In the cocaine group only at the $5 \mathrm{~min}$ time point was there a significant decrease in locomotor activity in the CMS group compared to the no stress group (Figure 3D: ${ }^{\star} p<0.05$; twoway ANOVA followed by Bonferroni post hoc test). The nicotine group showed a similar profile, locomotor activity was also significantly decreased in the CMS group compared to the no stress group at both the 5 and 10 min time point (Figure $4 \mathrm{D}:{ }^{*} p<0.05$; two-way ANOVA followed by Bonferroni post hoc test). Together, these results support the conclusion that CMS protects against subsequent KOR-mediated cocaine and nicotine reinstatement 


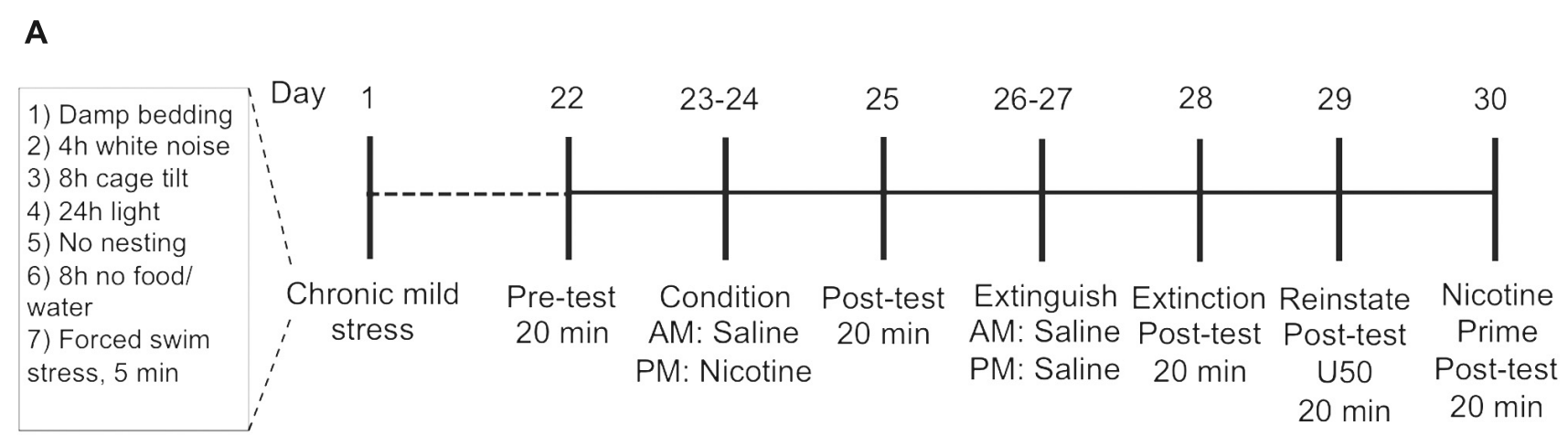

B C

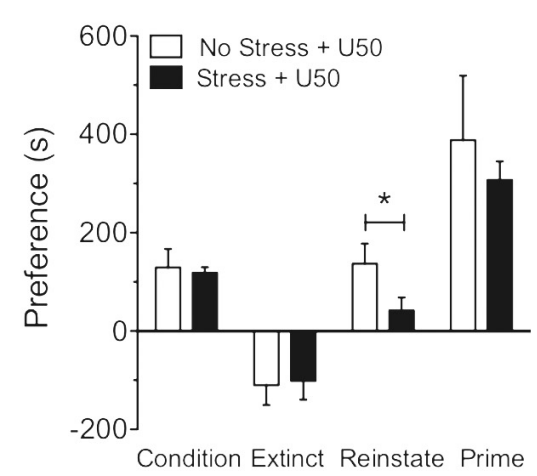

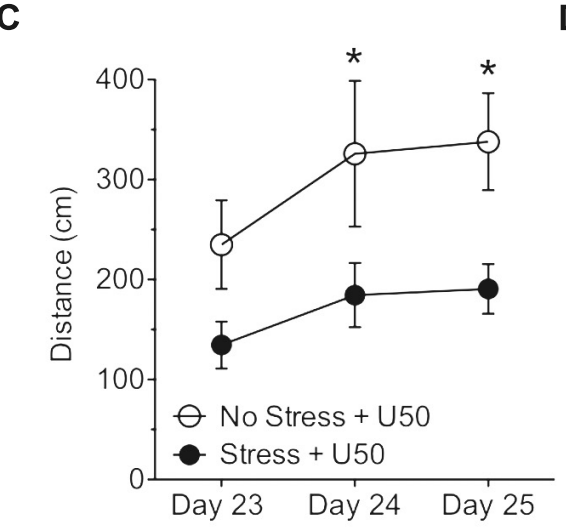

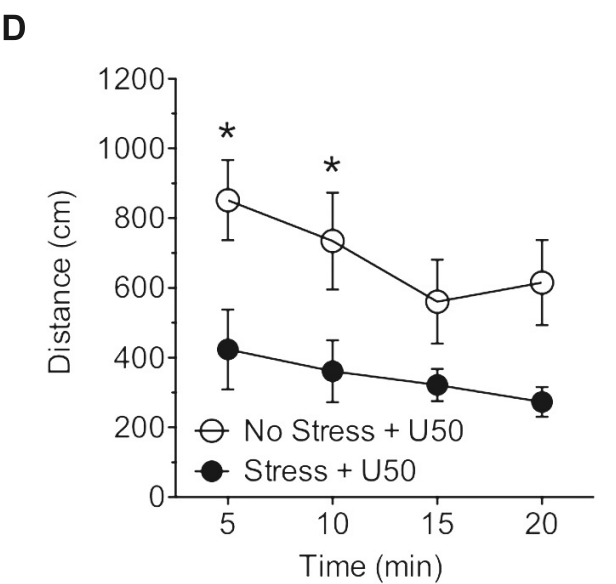

FIGURE 4 | Exposure to chronic mild stress blocks U50,488-induced but not nicotine-primed reinstatement of nicotine place preference.

(A) Timeline of nicotine place preference-reinstatement experiment. (B) Nicotine preference scores (day 26), calculated as post-test minus pre-test on the nicotine-paired side(condition), U50,488-induced (5 mg/kg, i.p.; reinstate, day 31$)$ and nicotine-induced $(0.5 \mathrm{mg} / \mathrm{kg}$, i.p) reinstatement (prime, day 32) scores of extinguished place preference. Data show a significant reinstatement of nicotine place preference following U50,488 in the no stress group. Groups are defined in the figures as their final reinstatement grouping
$(U 50=U 50,488)$. Data represent the mean preference $(s) \pm S E M, n=5-8$ $\left({ }^{*} p<0.05\right.$, Student's $t$-test). (C) Locomotor activity measured as distance traveled $(\mathrm{cm})$ during three cocaine conditioning days. Data represent the mean preference $(\mathrm{s}) \pm \mathrm{SEM}, n=5-8\left({ }^{*} p<0.05\right.$, no stress vs. chronic mild stress on days 24 and 25, respectively; two-way ANOVA followed by Bonferroni post hoc test). (D) Locomotor activity measured as distance traveled $(\mathrm{cm})$ during reinstatement. Data represent the mean preference (s) \pm SEM, $n=5-8{ }^{*} p<0.05$ at 5 min and 10 min time point in the no stress group vs. CMS group; two-way ANOVA followed by Bonferroni post hoc test). and further suggests that CMS may act to regulate KOR system function.

\section{DISCUSSION}

In the present study we investigated the interactions between various types of stress paradigms and how they influence KORinduced reinstatement of cocaine and nicotine preference. We determined the effects of a single acute stress, sub-chronic social defeat, and CMS on cocaine and nicotine conditioned place preference and KOR-induced reinstatement. Although, FSS, SDS, and CMS have all been implicated in regulating hedonic state and reward, the present report describes a previously unknown connection between prior stress exposure and KORmediated stress-induced behavior. Together, these findings suggest that various types of stress exposure act to influence the dynorphin/KOR-mediated reinstatement response, but they also demonstrate that prior CMS has no lasting effect on the rewarding properties of cocaine or nicotine in conditioned place preference paradigms.

Stress-induced opioid peptide release has been reported for three major opioid systems, and its release has been demonstrated to be associated with a variety of behavioral outputs including stress-induced analgesia, reinstatement, dysphoria, depression, and anxiety-like behaviors (Carlezon etal., 2006; Land et al., 2008; Bruchas et al., 2010; Chartoff et al., 2012; Al-Hasani et al., 2013). In these reports, animals are typically exposed to a single stress event (e.g., forced swim, social defeat, foot shock) and then KOR-mediated behaviors are measured following acute stress exposure (McLaughlin et al., 2003; Bruchas et al., 2011; Schindler et al., 2012). However, the stress experience over the course of an animal's lifetime is complex in nature occurring usually in multiple, randomized epochs. Therefore, the effects 
of CMS on KOR-mediated behavior remain an important area of investigation. Both repeated stress, and CMS models have been reported to induce dramatic changes in neural circuits and neuromodulator function (Hill et al., 2012; Lemos et al., 2012a,b; Tye et al., 2013), however, CMS effects on regulating cocaine-, nicotine-, and opioid-mediated conditioned preference behaviors is not known. Specifically, CMS-induced changes in serotonergic, noradrenergic, and dopaminergic signaling and release have all been reported (Rasheed et al., 2008; Vancassel et al., 2008; Hill et al., 2012) implicating important functions of monoamine regulation in CMS alterations of mood and reward seeking. In addition, it has been shown that repeated stress and CMS dramatically alter neuropeptidergic circuit function and impact neuropeptide modulation in subsequent stress responsivity, by either sensitizing the response or acting to facilitate desensitization. In the current report we found that following a single acute FSS, activation of KOR signaling caused potentiation of cocaine preference-reinstatement (Figure 1). In contrast, repeated SDS or CMS protected against subsequent KOR-mediated reinstatement (Figures 2, 3, and 4). We also found that this CMS protective effect not only influenced KOR-induced cocaine reinstatement (Figure 3) but it also blocked KOR-induced reinstatement of nicotine place preference (Figure 4), suggesting a conserved mechanism for multiple drugs of abuse. Interestingly, CMS exposure had no effect on the initial cocaine or nicotine conditioning, nor did CMS exposure impact the magnitude of drug-primed reinstatement. These findings suggest that SDS and CMS induce a type of "tolerance" to subsequent KOR activity, which has also been previously reported when administering repeated doses of KOR agonists (McLaughlin et al., 2004). Stress adaptability mechanisms are a critical consideration in our current findings because reports demonstrating that dramatic changes in neural circuit function include effects on KOR and corticotropin releasing factor (CRF) signaling following various types of repeated stress exposure (McEwen and Gianaros, 2011; Lemos et al., 2012a,b).

The precise neuronal and molecular mechanisms for SDS- and CMS-induced attenuation of KOR-induced reinstatement were not identified in this study but are important and exciting extensions of this work. There are a number of mechanisms that maybe involved in CMS-induced regulation of KOR-reinstatement. KOR regulation following repeated and high agonist-receptor occupancy has been previously reported to be mediated by GRK3 phosphorylation of serine 369 in mouse/rat KOR or serine 358 in the human KOR (Wang et al., 2003; McLaughlin et al., 2004; Bruchas et al., 2006, 2007a; Chen et al., 2007). In repeated SDS or CMS models it is possible that recurrent activation of KOR causes subsequent downregulation and desensitization of KOR signaling preventing further activation of KOR until full recovery. Furthermore, KOR regulation and deactivation (in contrast to mu-opioid receptors) take several weeks to recover as functional receptor entities (McLaughlin et al., 2004; Bruchas et al., 2007b), consistent with the CMS time course used in this study. Surprisingly the preventative effect of prior stress on KOR-mediated reinstatement did not also prevent KOR-induced decreases in locomotor activity (Figure 2C) suggesting that SDS acts in specific neural circuits associated with reinstatement but not locomotion. Therefore selective blockade of KORs in specific brain regions during repeated SDS, and CMS and subsequent measures of KOR-mediated behavioral responses will be required in future studies. In addition, utilizing GRK3 knockout mice, or expression of KOR-S369/358 mutants in vivo, and exposure to CMS are interesting extensions of this work as prior work has shown that GRK3 signaling is required for KOR-mediated behavioral effects via phosphorylation, arrestin recruitment, and p38 signaling (Bruchas et al., 2011). It has also been shown that KOR-mediated signaling to G-protein inwardly rectifying potassium channels in the serotonergic dorsal raphe nucleus (DRN) is altered following repeated stress exposure (Lemos et al., 2012a). Together, with the recent evidence that these circuits are implicated in KOR-induced reinstatement (Land et al., 2009; Bruchas et al., 2011) it is possible that CMS causes dysregulation of KOR signaling in the DRN to ultimately influence subsequent KOR-induced behavioral responses including reinstatement of drug seeking. Furthermore, CMS may cause downregulation of $\mathrm{KOR}$ in the locus coeruleus, a region which has recently been identified to play a key role in KORmediated reinstatement to cocaine place preference (Al-Hasani et al., 2013). However, these hypotheses will require further study using selective neural circuit dissection techniques.

The effects of stress on cocaine and nicotine seeking have been widely reported by numerous groups (for reviews see Koob, 2008; Aguilar et al., 2009). In the case of cocaine, it is well-established that stress and exposure to cues causes robust reinstatement of drug seeking in both animals models and human subjects (Koob and Kreek, 2007). The effects of stress on nicotine reinstatement in animal models are less well-characterized, although reports have shown that acute stress exposure potentiates nicotineseeking behavior and reinstates drug seeking (Buczek et al., 1999; Bilkei-Gorzo et al., 2008; Plaza-Zabala et al., 2010; Yamada and Bruijnzeel, 2011; Leão et al., 2012; Smith et al., 2012). It has also been established that human subjects widely report stress as the primary reason for their continued tobacco use (Bruijnzeel, 2012). However, the effects of randomized CMS on nicotine place preference in animal models has not been previously studied, nor have mechanisms of stress on KOR-induced regulation of nicotineinduced behavior been widely explored with the exception of some recent reports implicating KOR in nicotine-induced behavior (Smith et al., 2012; Jackson et al., 2013). Our current findings build on this prior work, and for the first time show that agonistinduced KOR activation is sufficient to cause reinstatement of nicotine CPP. Additionally, our finding that KOR agonist does not promote reinstatement of nicotine CPP following CMS suggests interesting and complex interactions between CMS and dynorphin/KOR neural circuits that are conserved for both nicotine and cocaine. However, whether similar neural circuits (e.g., dopaminergic, serotonergic) are required for KOR-dependent nicotine reinstatement as compared to cocaine reinstatement will require further investigation.

In summary, we report that frequency and duration of stress differentially influences KOR-induced reinstatement of cocaine and nicotine preference. The present study shows that repeated stress or CMS prior to reinstatement prevents a KOR-induced reinstatement response, while acute exposure to stress induces potentiation of KOR-reinstatement. The wide array of recent studies investigating the interactions between stress and KOR 
function on reward, reinstatement, and dysphoria suggest that KOR interacts with multiple neurotransmitter systems and circuits to mediate its complex role in behavioral output. We identified previously unrecognized roles for acute, sub-chronic, and chronic stress exposure on KOR-mediated behavioral function. These findings suggest that understanding the regulation of dynorphin/KOR systems in response to various stress exposures is critical to understanding and identifying KOR as a potentially novel therapeutic target system in drug relapse, anxiety, and depression.

\section{REFERENCES}

Aguilar, M. A., Rodríguez-Arias, M., and Miñarro, J. (2009). Neurobiological mechanisms of the reinstatement of drug-conditioned place preference. Brain Res. Rev. 59, 253-277. doi: 10.1016/j.brainresrev.2008.08.002

Al-Hasani, R., and Bruchas, M. R. (2011). Molecular mechanisms of opioid receptor-dependent signaling and behavior. Anesthesiology 115, 1363-1381. doi: 10.1097/ ALN.0b013e318238bba6

Al-Hasani, R., McCall, J. G., Foshage, A. M., and Bruchas, M. R. (2013). Locus coeruleus kappa opioid receptors modulate reinstatement of cocaine place preference through a noradrenergic mechanism. Neuropsychopharmacology doi: 10.1038/npp.2013.151 [Epub ahead of print].

Beardsley, P. M., Howard, J. L., Shelton, K. L., and Carroll, F. I. (2005). Differential effects of the novel kappa opioid receptor antagonist, JDTic, on reinstatement of cocaine-seeking induced by footshock stressors vs cocaine primes and its antidepressant-like effects in rats. Psychopharmacology (Berl.) 183, 118-126. doi: 10.1007/s00213-0050167-4

Bergström, A., Jayatissa, M. N., Mørk, A., and Wiborg, O. (2008). Stress sensitivity and resilience in the chronic mild stress rat model of depression; an in situ hybridization study. Brain Res. 1196, 41-52. doi: 10.1016/j.brainres.2007.12.025

Bertrand, E., Smadja, C., Mauborgne, A., Roques, B. P., and Daugé, V. (1997). Social interaction increases the extracellular levels of [Met]enkephalin in the nucleus accumbens of control but not of chronic mild stressed rats. Neuroscience 80, 17-20.

Bilkei-Gorzo, A., Rácz, I., Michel, K., Darvas, M., Maldonado, R., and Zimmer, A. (2008). A common genetic predisposition to stress sensitivity and stress-induced nicotine craving. Biol. Psychiatry 63, 164-171. doi:10.1016/j.biopsych.2007.02.010

Bruchas, M. R., Land, B. B., Aita, M., Xu, M., Barot, S. K., Li, S., et al. (2007a).
Stress-induced p38 mitogenactivated protein kinase activation mediates kappa-opioid-dependent dysphoria. J. Neurosci. 27, 11614 11623. doi: 10.1523/JNEUROSCI. 3769-07.2007

Bruchas, M. R., Yang, T., Schreiber, S., Defino, M., Kwan, S. C., Li, S., et al. (2007b). Long-acting kappa opioid antagonists disrupt receptor signaling and produce noncompetitive effects by activating c-Jun $\mathrm{N}$ terminal kinase. J. Biol. Chem. 282, 29803-29811. doi: 10.1074/jbc.M705 540200

Bruchas, M. R., Land, B. B., and Chavkin, C. (2010). The dynorphin/kappa opioid system as a modulator of stress-induced and pro-addictive behaviors. Brain Res. 1314, 44-55. doi: 10.1016/j.brainres. 2009.08.062

Bruchas, M. R., Macey, T. A., Lowe, J. D., and Chavkin, C. (2006). Kappa Opioid Receptor Activation of p38 MAPK Is GRK3and Arrestin-dependent in Neurons and Astrocytes. J. Biol. Chem. 281, 18081-18089. doi: 10.1074/ jbc.M513640200

Bruchas, M. R., Schindler, A. G. Shankar, H., Messinger, D. I., Miyatake, M., Land, B. B., et al. (2011). Selective $\mathrm{p} 38 \alpha$ MAPK deletion in serotonergic neurons produces stress resilience in models of depression and addiction. Neuron 71, 498-511. doi: 10.1016/j.neuron.2011.06.011

Bruijnzeel, A. W. (2012). Tobacco addiction and the dysregulation of brain stress systems. Neurosci. Biobehav. Rev. 36, 1418 1441. doi: 10.1016/j.neubiorev.2012. 02.015

Buczek, Y., Lê, A. D., Wang, A., Stewart, J., and Shaham, Y. (1999). Stress reinstates nicotine seeking but not sucrose solution seeking in rats. Psychopharmacology (Berl.) 144, 183188.

Carlezon, W. A. Jr., Béguin, C., DiNieri, J. A., Baumann, M. H., Richards, M. R., Todtenkopf, M. S., et al. (2006). Depressive-like effects of the kappaopioid receptor agonist salvinorin A on behavior and neurochemistry in

\section{ACKNOWLEDGMENTS}

These studies were supported by NIDA grant R01DA033396-A1, R00-DA025182 (to Michael R. Bruchas), McDonnell Center for Systems Neuroscience (MRB), NIMH F31MH101956 (Jordan G. McCall), WUSTL DBBS (Jordan G. McCall). We thank the NIDA drug program for providing U50,488 and cocaine $\mathrm{HCl}$. We thank the members of the Bruchas laboratory for helpful discussion and technical assistance. We also thank Marina Picciotto (Yale) for technical advice.

rats. J. Pharmacol. Exp. Ther. 316, 440-447.

Chartoff, E., Sawyer, A., Rachlin, A., Potter, D., Pliakas, A., and Carlezon, W. A. (2012). Blockade of kappa opioid receptors attenuates the development of depressive-like behaviors induced by cocaine withdrawal in rats. Neuropharmacology 62, 167176. doi: 10.1016/j.neuropharm.2011. 06.014

Chen, Y., Chen, C., and Liu-Chen, L.-Y. (2007). Dynorphin peptides differentially regulate the human kappa opioid receptor. Life Sci. 80, 1439-1448. doi: 10.1016/j.lfs.2007.01.018

Covington, H. E. III, and Miczek, K. A. (2001). Repeated social-defeat stress, cocaine or morphine. Effects on behavioral sensitization and intravenous cocaine self-administration "binges." Psychopharmacology (Berl.) 158, 388-398. doi: 10.1007/s00213 0100858

Ebner, S. R., Roitman, M. F., Potter, D. N., Rachlin, A. B., and Chartoff, E. H. (2010). Depressive-like effects of the kappa opioid receptor agonist salvinorin A are associated with decreased phasic dopamine release in the nucleus accumbens. Psychopharmacology (Berl.) 210, 241-252. doi: 10.1007/s00213-010-1836-5

Elizalde, N., Gil-Bea, F. J., Ramírez, M. J., Aisa, B., Lasheras, B., Del Rio, J., et al. (2008). Long-lasting behavioral effects and recognition memory deficit induced by chronic mild stress in mice: effect of antidepressant treatment. Psychopharmacology (Berl.) 199, 1-14. doi: 10.1007/s00213-0071035-1

Gehrke, B. J., Chefer, V. I., and Shippenberg, T. S. (2008). Effects of acute and repeated administration of salvinorin A on dopamine function in the rat dorsal striatum. Psychopharmacology (Berl.) 197, 509-517. doi: 10.1007/s00213-007-1067-6

Giros, B., Jaber, M., Jones, S. R., Wightman, R. M., and Caron, M. G. (1996). Hyperlocomotion and indifference to cocaine and amphetamine in mice lacking the dopamine transporter. Nature 379, 606-612. doi: $10.1038 / 379606 \mathrm{a} 0$
Graziane, N. M., Polter, A. M., Briand, L. A., Pierce, R. C., and Kauer, J. A. (2013). Kappa opioid receptors regulate stressinduced cocaine seeking and synaptic plasticity. Neuron 77, 942-954. doi: 10.1016/j.neuron.2012.12.034

Hill, M. N., Hellemans, K. G. C., Verma, P., Gorzalka, B. B., and Weinberg, J. (2012). Neurobiology of chronic mild stress: parallels to major depression. Neurosci. Biobehav. Rev. 36, 2085-2117. doi: 10.1016/j.neubiorev.2012.07.001

Jackson, K. J., McLaughlin, J. P., Carroll, F. I., and Damaj, M. I. (2013). Effects of the kappa opioid receptor antagonist, norbinaltorphimine, on stress and drug-induced reinstatement of nicotine-conditioned place preference in mice. Psychopharmacology (Berl.) 226, 763-768. doi: 10.1007/s00213-012-2716-y

Koob, G., and Kreek, M. J. (2007). Stress, dysregulation of drug reward pathways, and the transition to drug dependence. Am. J. Psychiatry 164, 1149-1159. doi: 10.1176/ appi.ajp.2007.05030503

Koob, G. F. (2008). A role for brain stress systems in addiction. Neuron 59, 11-34. doi: 10.1016/ j.neuron.2008.06.012

Land, B. B., Bruchas, M. R., Lemos, J. C., Xu, M., Melief, E. J., and Chavkin, C. (2008). The dysphoric component of stress is encoded by activation of the dynorphin kappaopioid system. J. Neurosci. 28, 407414. doi: 10.1523/JNEUROSCI.445807.2008

Land, B. B., Bruchas, M. R., Schattauer, S., Giardino, W. J., Aita, M., Messinger, D., et al. (2009). Activation of the kappa opioid receptor in the dorsal raphe nucleus mediates the aversive effects of stress and reinstates drug seeking. Proc. Natl. Acad. Sci. U.S.A. 106, 19168-19173. doi: 10.1073/pnas.0910705106

Leão, R. M., Cruz, F. C., Marin, M. T., and Planeta Cda, S. (2012). Stress induces behavioral sensitization, increases nicotine-seeking behavior and leads to a decrease of CREB in the nucleus accumbens. Pharmacol. 
Biochem. Behav. 101, 434-442. doi: 10.1016/j.pbb.2012.01.025

Lemos, J. C., Roth, C. A., Messinger, D. I., Gill, H. K., Phillips, P. E. M., and Chavkin, C. (2012a). Repeated stress dysregulates $\kappa$-opioid receptor signaling in the dorsal raphe through a p38 $\alpha$ MAPKdependent mechanism. J. Neurosci. 32, 12325-12336. doi: 10.1523/ JNEUROSCI.2053-12.2012

Lemos, J. C., Wanat, M. J., Smith, J. S., Reyes, B. A. S., Hollon, N. G., Van Bockstaele, E. J., et al. (2012b). Severe stress switches CRF action in the nucleus accumbens from appetitive to aversive. Nature 490, 402-406. doi: 10.1038/nature 11436

McEwen, B. S., and Gianaros, P. J. (2011). Stress- and allostasis-induced brain plasticity. Annu. Rev. Med. 62, 431-445. doi: 10.1146/annurev-med052209-100430

McLaughlin, J. P., Land, B. B., Li, S., Pintar, J. E., and Chavkin, C. (2006). Prior activation of kappa opioid receptors by U50,488 mimics repeated forced swim stress to potentiate cocaine place preference conditioning. Neuropsychopharmacology 31, 787-794. doi: 10.1038/sj.npp.1300860

McLaughlin, J. P., Marton-Popovici, M., and Chavkin, C. (2003). Kappa opioid receptor antagonism and prodynorphin gene disruption block stress-induced behavioral responses. J. Neurosci. 23, 5674-5683.

McLaughlin, J. P., Myers, L. C., Zarek, P. E., Caron, M. G., Lefkowitz, R. J., Czyzyk, T. A., et al. (2004). Prolonged kappa opioid receptor phosphorylation mediated by G-protein receptor kinase underlies sustained analgesic tolerance. J. Biol. Chem. 279, 1810 1818. doi: 10.1074/jbc.M305796200

Peng, Y.-L., Liu, Y.-N., Liu, L., Wang, X., Jiang, C.-L., and Wang, Y.-X. (2012). Inducible nitric oxide synthase is involved in the modulation of depressive behaviors induced by unpredictable chronic mild stress. J. Neuroinflammation 9, 75. doi: 10.1186/1742-2094-9-75

Plaza-Zabala, A., Martín-García, E., de Lecea, L., Maldonado, R., and Berrendero, F. (2010). Hypocretins regulate the anxiogenic-like effects of nicotine and induce reinstatement of nicotine-seeking behavior. J. Neurosci. 30, 2300-2310. doi: $10.1523 /$ JNEUROSCI.572409.2010

Potter, D. N., Damez-Werno, D., Carlezon, W. A. Jr., Cohen, B. M., and Chartoff, E. H. (2011). Repeted exposure to kappa-opioid receptor agonist salvinorin A modulates extracellular signal-regulated kinase and reward sensitivity. Biol. Psychiatry 70, 744-753. doi: 10.1016/ j.biopsych.2011.05.021

Rasheed, N., Tyagi, E., Ahmad, A., Siripurapu, K. B., Lahiri, S., Shukla, R., et al. (2008). Involvement of monoamines and proinflammatory cytokines in mediating the anti-stress effects of Panax quinquefolium. $J$. Ethnopharmacol. 117, 257-262. doi: 10.1016/j.jep.2008.01.035

Redila, V. A., and Chavkin, C. (2008). Stress-induced reinstatement of cocaine seeking is mediated by the kappa opioid system. Psychopharmacology (Berl.) 200, 59-70. doi: 10.1007/s00213-008-1122-y

Reith, M. E. (1986). Effect of repeated administration of various doses of cocaine and WIN 35,065-2 on locomotor behavior of mice. Eur. J. Pharmacol. 130, 65-72. doi: 10.1016/0014-2999(86)90184-6

Schindler, A. G., Messinger, D. I., Smith, J. S., Shankar, H., Gustin, R. M., Schattauer, S. S., et al. (2012). Stress produces aversion and potentiates cocaine reward by releasing endogenous dynorphins in the ventral striatum to locally stimulate serotonin reuptake. J. Neurosci. 32, 17582-17596. doi: 10.1523/ JNEUROSCI.3220-2.2012

Smith, J. S., Schindler, A. G., Martinelli, E., Gustin, R. M., Bruchas, M. R., and Chavkin, C. (2012). Stress-induced activation of the dynorphin/к-opioid receptor system in the amygdala potentiates nicotine conditioned place preference. J. Neurosci. 32, 1488-1495. doi: 10.1523/JNEUROSCI.298011.2012

Sora, I., Wichems, C., Takahashi, N., Li, X. F., Zeng, Z., Revay, R., et al. (1998). Cocaine reward models: conditioned place preference can be established in dopamine- and in serotonintransporter knockout mice. Proc. Natl. Acad. Sci. U.S.A. 95, 7699-7704. doi: 10.1073/pnas.95.13.7699

Tolliver, B. K., Belknap, J. K., Woods, W. E., and Carney, J. M. (1994). Genetic analysis of sensitization and tolerance to cocaine. J. Pharmacol. Exp. Ther 270, 1230-1238.

Tye, K. M., Mirzabekov, J. J., Warden, M. R., Ferenczi, E. A., Tsai, H.-C., Finkelstein, J., et al. (2013). Dopamine neurons modulate neural encoding and expression of depression-related behaviour. Nature 493, 537-541. doi: 10.1038 /nature 11740

Tzschentke, T. M. (2007). Measuring reward with the conditioned place preference (CPP) paradigm: update of the last decade. Addict. Biol. 12, 227-462. doi: 10.1111/j.13691600.2007.00070.x

Van Bockstaele, E. J., Reyes, B. A. S., and Valentino, R. J. (2010). The locus coeruleus: a key nucleus where stress and opioids intersect to mediate vulnerability to opiate abuse. Brain Res. 1314, 162 174. doi: 10.1016/j.brainres.2009. 09.036

Vancassel, S., Leman, S., Hanonick, L., Denis, S., Roger, J., Nollet, M., et al. (2008). n-3 polyunsaturated fatty acid supplementation reverses stress-induced modifications on brain monoamine levels in mice. J. Lipid Res. 49, 340-348. doi: 10.1194/jlr.M700328JLR200

Walker, B. M., and Koob, G. F. (2008). Pharmacological evidence for a motivational role of kappa-opioid systems in ethanol dependence. Neuropsychopharmacology 33, 643-652. doi: 10.1038/sj.npp. 1301438

Walker, B. M., Zorrilla, E. P., and Koob, G. F. (2011). Systemic к-opioid receptor antagonism by nor-binaltorphimine reduces dependence-induced excessive alcohol self-administration in rats. Addict. Biol. 16, 116119. doi: 10.1111/j.1369-1600.2010. 00226.x

Wang, Y., Li, J.-G., Huang, P., Xu, W., and Liu-Chen, L.-Y. (2003) Differential effects of agonists on adenylyl cyclase superactivation mediated by the kappa opioid receptors: adenylyl cyclase superactivation is independent of agonist-induced phosphorylation, desensitization, internalization, and down-regulation. J. Pharmacol. Exp. Ther. 307, 1127-1134. doi: 10.1124/ ipet.103.055814

Wee, S., and Koob, G. F. (2010). The role of the dynorphin-kappa opioid system in the reinforcing effects of drugs of abuse. Psychopharmacology (Berl.) 210, 121-135. doi: 10.1007/s00213010-1825-8

Williams, J. T., Ingram, S. L., Henderson, G., Chavkin, C., von Zastrow, M. Schulz, S., et al. (2013). Regulation of $\mu$-opioid receptors: desensitization, phosphorylation, internalization, and tolerance. Pharmacol. Rev. 65, 223-254. doi: 10.1124/pr.112. 005942
Wise, R. A. (2004). Dopamine, learning and motivation. Nat. Rev. Neurosci. 5, 483-494. doi: 10.1038/ nrn1406

Yamada, H., and Bruijnzeel, A. W. (2011). Stimulation of $\alpha 2$-adrenergic receptors in the central nucleus of the amygdala attenuates stress-induced reinstatement of nicotine seeking in rats. Neuropharmacology 60, 303311. doi: 10.1016/j.neuropharm.2010. 09.013

Zhang, Y., Butelman, E. R., Schlussman, S. D., Ho, A., and Kreek, M. J. (2005). Effects of the plantderived hallucinogen salvinorin A on basal dopamine levels in the caudate putamen and in a conditioned place aversion assay in mice: agonist actions at kappa opioid receptors. Psychopharmacology (Berl.) 179, 551-558. doi: 10.1007/s00213-0042087-0

Zhang, Y., Mantsch, J. R., Schlussman, S. D., Ho, A., and Kreek, M. J. (2002). Conditioned place preference after single doses or "binge" cocaine in C57BL/6J and 129/J mice. Pharmacol. Biochem. Behav. 73, 655662. doi: 10.1016/S0091-3057(02) 00859-6

Conflict of Interest Statement: The authors declare that the research was conducted in the absence of any commercial or financial relationships that could be construed as a potential conflict of interest.

Received: 28 May 2013; accepted: 16 July 2013; published online: 06 August 2013.

Citation: Al-Hasani R, McCall JG and Bruchas MR (2013) Exposure to chronic mild stress prevents kappa opioidmediated reinstatement of cocaine and nicotine place preference. Front. Pharmacol. 4:96. doi: 10.3389/fphar.2013. 00096

This article was submitted to Frontiers in Neuropharmacology, a specialty of Frontiers in Pharmacology.

Copyright (c) 2013 Al-Hasani, McCall and Bruchas. This is an open-access article distributed under the terms of the Creative Commons Attribution License (CC BY). The use, distribution or reproduction in other forums is permitted, provided the original author(s) or licensor are credited and that the original publication in this journal is cited, in accordance with accepted academic practice. No use, distribution or reproduction is permitted which does not comply with these terms. 